\title{
O DISCURSO DE PARTO DE MULHERES VIVENCIANDO A EXPERIÊNCIA DA PRIMEIRA GESTAÇÃO*
}

\author{
Marcia R. Nozawa** \\ Néia Schor" *
}

\begin{abstract}
Resumo: Este trabalho é parte integrante de um estudo realizado junto a um grupo de mulheres, clientes de um centro de saúde escola, que vivenciavam a experiência da primeira gravidez, com o objetivo de desenvolver e avaliar uma ação educativa participante. $A$ ação educativa foi desenvolvida sob a perspectiva de uma relação pedagógica calcada no diálogo e na participação ativa das educandas no processo, assim, o referencial metodológico do estudo inspirou-se na concepção de educação libertadora e na metodologia participativa em pesquisa. Os dados apresentados e a análise realizada referem-se à discussão sobre o parto que apresentou-se como tema central durante todo o processo educativo. Pelo emprego da Análise de Discurso como instrumento de avaliação da ação realizada foi possivel identificar o sentido predominantemente negativo de parto no discurso das gestantes, bem como discutir o processo de constituição desse discurso apontando estratégias que promovam a superação de tal significado visando subsidiar a prática educativa realizada por profissionais de saúde junto a esse grupo especifico da clientela.
\end{abstract}

Palavras-chave: Primeira gestação; ação educativa; análise de discurso; educação libertadora; metodologia participativa em pesquisa.

* Este artigo está baseado na dissertação de mestrado intitulada Ação Educativa Participante com Gestantes: A Análise de Discurso como Instrumento de Avaliação, apresentada no ano de 1991, à Faculdade de Saúde Pública da Universidade de São Paulo.

** Departamento de Enfermagem da Faculdade de Ciências Médicas da UNICAMP, Cidade Universitária "Zeferino Vaz", Barão Geraldo, Campinas, SP. Endereço para correspondència: Rua Uruguaiana, 1237/21 - Bosque, 13026002 - Campinas, SP.

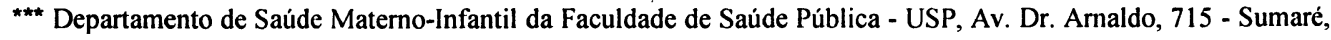
01246-904 - São Paulo, SP, Capital. 


\section{INTRODUÇÃO}

A origem deste estudo teve por base questões que surgiram de discussões e reflexões sobre o cotidiano vivido no contexto da assistência à saúde da mulher gestante.

A primeira questão emergiu da reflexão sobre a forma pela qual o modelo atual de assistência à saúde, em decorrência, a organização dos serviços acabam por reduzir a assistência à maternidade ao cuidado exclusivo com o corpo grávido da mulher, visando sobretudo a vitalidade do concepto. Ao constatar a gravidez, a mulher é encaminhada ao pré-natal e, assim, começa a ser submetida a uma sucessão de procedimentos que se destinam a medir as dimensões físicas, avaliar as funções do corpo materno e comparar os dados obtidos aos parâmetros orgânicos de normalidade, desejáveis a uma boa evolução da gestação e parto, tendo em vista, prioritariamente, a garantia das condições vitais do feto e da criança, em detrimento de uma assistência que também contemple as necessidades e expectativas manifestadas pelas mulheres.

Segundo MALDONADO(1976) a sofisticação progressiva da assistência pré e perinatal, decorrente do avanço tecnológico da obstetrícia, permitiu uma redução considerável dos riscos maternos e fetais, entretanto, promoveu uma profunda desagregação entre os aspectos orgânico e emocional no atendimento clínico às gestantes. Da mesma forma, XAVIER(1987) ressalta que com o crescimento da taxa de partos hospitalares a atenção médica prioriza cada vez mais os cuidados com a gestação e o recém-nascido em detrimento do cuidado com a própria mulher parturiente.

KITZINGER(1987) observa também que nas sociedades ocidentais a futura mãe tornou-se objeto da obstetrícia à medida que, assumindo o controle exclusivo sobre o desenvolvimento fetal e o nascimento da criança, desapropriou o grupo familiar e a comunidade do direito de intervirem no processo. Se a gravidez numa sociedade primitiva 
se constituía em alvo de sansões e restrições à futura mãe, a nossa sociedade pode provocar uma ansiedade ainda maior com a sucessão infindável de exames, cálculos e intervenções obstétricas constantes. Assim, ressalta a autora, torna-se compreensível o fato de que grande parte das mulheres percebam seus corpos como meros recipientes para o feto e, por vezes até como obstáculo ao fácil acesso de técnicas diagnósticas. A utilização muitas vezes indiscriminada de procedimentos para avaliação diagnóstica da vitalidade do feto, sem referência à assistência à mulher como pessoa, pode causar confusão e angústia nas gestantes. Uma consequência deste fato é a falta de confiança de grande parte das mulheres em sua capacidade de gerar e dar a luz à crianças sadias sem a ajuda do médico.

Do mesmo modo, as consultas de pré-natal não constituem espaço de resposta aos anseios e inseguranças das mulheres gestantes. De um lado, os médicos alegam freqüentemente a falta de tempo e de habilidade para promoverem uma interação e troca de experiências com a clientela durante a consulta médica. De outro lado, não são raras as vezes em que, ao saírem do consultório médico, as gestantes permaneçam com uma série de dúvidas relativas ao processo que vivenciam dado à dificuldade em expressar seus anseios em decorrência da complicada relação médico-paciente que comumente se estabelece. Assim, com relativa frequência, observamos que 0 constrangimento provocado pela relação médico-cliente distanciada e o receio em sobrecarregar ainda mais o trabalho do médico, determinam um bloqueio à livre manifestação das dúvidas e preocupações das mulheres.

$\mathrm{Na}$ abordagem da psicologia a gestação é revestida de grande relevância por representar um momento existencial de extrema importância no ciclo vital da mulher, à exemplo da adolescência e do climatério, em função das perspectivas de mudanças em seu papel social e da necessidade de adaptações e ajustamentos requeridos nesse 
processo. Aliado a essa questão mais específica, os temores, medos e receios decorrentes do desconhecimento das modificações orgânicas e emocionais próprias ao processo da gestação são expressados com bastante freqüência, em especial, os temores relativos ao momento do parto.

Considerando essas questões levantadas, torna-se difícil negar a importância do trabalho educativo com as mulheres gestantes, em especial com as gestantes primigestas que por não contarem com a experiência prévia, podem estar mais sujeitas às inseguranças decorrentes do não domínio da situação. Contudo, as ações educativas desenvolvidas pelos serviços de saúde poderiam ser muito significativas se estruturadas a partir da identificação de necessidades do próprio grupo a que se destina.

Neste sentido, a identificação e análise do significado do parto entre as mulheres gestantes que freqüentam o serviço pode trazer contribuições concretas em direção à organização de ações educativas voltada a atender aos interesses dessa clientela.

É importante salientar ainda que, na qualidade de profissional de saúde no exercício da função docente junto ao ensino de enfermagem, estamos inseridos no contexto da assistência à saúde da população em centros de saúde. Deste modo, entendemos que o presente estudo consolida a integração das atividades essenciais da docência, ou seja, ensino, pesquisa e extensão, em uma área prioritária de investigação. Assim, pretendemos que os resultados deste estudo possam trazer contribuições no repensar da prática educativa no contexto da saúde da mulher, no âmbito do ensino e do serviço.

Este estudo, que se propõe a identificar o discurso de parto enunciado por mulheres vivenciando a experiência da primeira gestação bem como a analisar seu processo de constituição pelo emprego da Análise de Discurso, faz parte de uma pesquisa 
realizada por NOZAWA(1991) que teve por objetivo desenvolver e avaliar uma ação educativa participante com um grupo de mulheres primigestas.

A ação educativa proposta naquela pesquisa foi desenvolvida segundo uma perspectiva que compreende a educação em saúde enquanto espaço concreto de interação e troca de conhecimentos entre o profissionais e usuários dos serviços de saúde. Deste modo, o conhecimento acumulado de experiências vividas e as expectativas das mulheres gestantes representaram a base sobre a qual o processo educativo desenvolveu-se.

\section{QUADRO TEÓRICO-METODOLÓGICO}

Uma ação educativa que se constitua enquanto espaço de interação e troca de conhecimentos deve valorizar prioritariamente a expectativa e a vivência individual e coletiva e pressupõe uma relação calcada no diálogo e na participação dos educandos no processo. Neste sentido, este estudo inspirou-se na metodologia de pesquisa participante e na concepção de educação problematizadora desenvolvida por Paulo Freire.

A Análise de Discurso (AD) empregada neste estudo, fundamenta-se, de acordo com PÊCHEUX(1987), na articulação de três regiões do conhecimento:

- o materialismo histórico, como teoria das formações sociais concretas e de suas transformações, estando nela incluída a ideologia;

- a lingüística como teoria dos mecanismos sintáticos e de enunciação;

- a teoria do discurso, como teoria da determinação histórica dos processos semânticos; atravessados, ainda, por uma teoria da subjetividade, de natureza psicanalitica. 
O campo de reflexão da $A D$ situa-se nas condições de produção e de apreensão da significação de textos visando, fundamentalmente, compreender o modo de funcionamento, os princípios organizadores e formas de produção social do sentido.

Nessa perspectiva, a linguagem é entendida como trabalho simbólico que se constrói na relação que o homem estabelece com sua realidade natural e social.

A AD busca determinar os processos históricos sociais em jogo na constituição da linguagem, a partir de duas noções fundamentais: a noção de sistema lingüístico enquanto conjunto de estruturas fonológicas, morfológicas e sintáticas, dotado de relativa autonomia, e a noção de processo discursivo-ideológico que se desenvolve sobre a base de leis internas que regem o sistema lingüístico. O processo discursivo-ideológico é um conceito elaborado a partir da noção de sistema de formação, desenvolvida por Foucault, que Pêcheux procura inscrever em uma relação com a ideologia de classes, entendendo que se a língüa tem relativa autonomia em relação ao discurso e à luta de classes sociais, as mesmas utilizam a lingüa conforme seus interesses antagônicos(PÊCHEUX, 1988).

Da distinção entre base lingüistica e processo discursivo ideológico resulta o conhecimento de que a língua, como invariante pressuposta por condições de produção existentes em um dado momento histórico, permite a possibilidade material de produção do discurso e que os processos discursivos representam a fonte de produção dos efeitos de sentido no discurso.

Deste modo, a $A D$ entende que o processo de constituição de qualquer seqüência verbal é determinada por suas condições de produção, ou seja, pelos interlocutores, pelo contexto histórico, social e ideológico e pela formação discursiva na qual é produzida. Formação discursiva é o que numa dada formação ideológica (numa dada posição em uma dada conjuntura determinada pela luta de classes) determina o que pode e o deve 
ser dito(PÊCHEUX, 1988).

Assim, as palavras mudam de sentido segundo as posições sociais sustentadas por aqueles que as empregam, ou seja, elas adquirem seu sentido em referência a essas posições, às formações ideológicas nas quais essas posições se inscrevem. Formação ideológica segundo Haroche e col., (1971), citado por ORLANDI(1987) constitui um conjunto de atitudes e representações que não são nem individuais nem coletivas mas que se reportam mais ou menos diretamente às posições de classe em conflito umas com as outras. (pg. 27) As formações ideológicas são compostas por uma ou mais formações discursivas interligadas.

Segundo PÊCHEUX(1988), a ideologia afeta o sujeito, por meio de dois tipos de esquecimento, criando uma realidade discursiva ilusória. Pelo esquecimento $n^{0} 1,0$ sujeito se coloca como origem exclusiva de seu discurso, apagando, inconscientemente, qualquer indício que remeta seu discurso ao exterior da sua formação discursiva e passa a crer na ilusão de que é o criador absoluto do seu discurso, quando, na realidade, apenas retoma sentidos pré-existentes. É neste sentido que ORLANDI(1988) entende que todo discurso nasce em outro discurso que the serve de matéria prima e, por sua vez, possibilita outro discurso, seu futuro discursivo. Essa relação de sentidos de um discurso com outros discursos é contemplada pela concepção de intertextualidade.

Pelo esquecimento $n^{\circ} 2$, que se refere a um processo pré-consciente ou consciente, o sujeito falante seleciona formas e seqüências no interior da formação discursiva que o domina e oculta outras formas e seqüências possiveis. Essa operação produz no sujeito a ilusão de que seu discurso reflete o conhecimento objetivo que tem da realidade.

Ao reconhecer o desdobramento de papéis ou diferentes posições ocupadas pelo sujeito em um texto, a AD posiciona-se contrariamente a ilusão de sujeito centrado, 
sujeito como fonte ou origem do sentido. Em relação a isso, ORLANDI(1988), entende o discurso como o lugar da dispersão de textos, ao considerar a possibilidade de um discurso veicular sentidos de várias formações discursivas. Do mesmo modo, a autora considera o texto como o lugar de dispersão do sujeito que, ao ocupar diferentes posições de enunciação, perde sua centralidade como sujeito único.

A Análise de Discurso, ao considerar a exterioridade que toma parte na constituição do discurso, parte do texto, sua unidade analítica, da historicidade nele contida, para apreender o modo pelo qual se dá a sua relação com o exterior. Se o contexto constitui o discurso, ele pode ser atestado no próprio texto, em sua materialidade, que é de natureza histórico-social(ORLANDI,1987).

Ao observar a linguagem em seu contexto, ORLANDI(1988) considera que, de modo geral, o discurso é produzido pela articulação de dois grandes processos fundamentais na constituição da linguagem. O processo polissêmico responsável pela possibilidade constante de existirem sentidos diferentes, múltiplos, e o processo parafrástico que é aquele que permite a produção do mesmo sentido sob várias formas. As várias instâncias da linguagem são constituidas pela tensão que se estabelece entre o mesmo e o diferente. Ai se situa a relação entre a variação, a multiplicidade inerente à linguagem e a sua contenção (institucional). Assim se expressa o conflito entre o garantido, o institucionalizado, o legitimado, e aquilo que, no domínio do múltiplo, tem de se garantir, se legitimar, se institucionalizar. A polissemia é o conceito que permite a tematização do deslocamento daquilo que na linguagem representa o garantido, o sedimentado. Esta tensão básica, na perspectiva do discurso, é a que existe entre o texto e o contex to histórico-social: porque a linguagem é sócio-historicamente constituída, ela muda, e pela mesma razão ela se mantém a mesma.(ORLANDI, 1988:19-20).

Admitindo a dispersão do sujeito a $A D$ considera que a heterogeneidade é 
constitutiva do próprio discurso. A heterogeneidade, principio teórico da Análise de Discurso, é a concepção de que a constituição do texto não é homogênea, ela se dá na relação radical de seu interior com seu exterior. A problematização desse pressuposto levou ao aprimoramento do principio de autoria, segundo o qual cabe ao autor imprimir coerência, unidade e completude ao texto, harmonizando, ocultando ou domesticando as vozes divergentes.

Há formas que podem ser manobradas por um discurso que marcam sua relação com o seu exterior, é a heterogeneidade mostrada. A heterogeneidade mostrada, de acordo com MAINGUENEAU(1989) é aquela que incide sobre as manifestações recuperáveis no texto a partir da diversidade de fontes de enunciação, a polifonia. $A$ polifonia, concepção específica da heterogeneidade, é a noção de que na enunciação existem dois tipos de personagens, os enunciadores, que são aqueles cujas vozes estejam presentes na enunciação embora não seja possivel atribuir-lhes palavras precisas, e os locutores, que se apresentam como os responsáveis pelo discurso.

Alguns fenômenos de importância considerável para a Análise de Discurso, tais como, a pressuposição e a negação, podem ser igualmente objeto de análise por meio da polifonia.

Por outro lado, há um nivel de heterogeneidade constitutiva do discurso, que o relaciona ao interdiscurso que, por seu turno, corresponde à memória discursiva à qual toda formação discursiva se associa e é constituída de formulações que repetem, recusam e transformam outras formulações.

COURTINE (1982) citado por LAGAZZI(1987) define o interdiscurso como o domínio de saber próprio a uma formação discursiva, que determina o que pode e deve ser dito e exclui o não-formulável. Incorpora os elementos pré-construídos, produzidos fora dela, mas que atuam como se sempre estivessem lá. 
A formulação de um enunciado estaria colocada, de alguma forma no cruzamento de dois eixos: um eixo do pré-construido, do domínio de memória e outro eixo de constituição do enunciado, que oculta o primeiro eixo, uma vez que o sujeito que enuncia é produzido de forma a interiorizar, ilusoriamente, o pré-construído que sua formação discursiva impõe(MAINGUENEAU, 1989).

Dando cumprimento aos objetivos propostos neste estudo, utilizamos a Análise de Discurso por meio do emprego dos conceitos de processos parafrástico e polissêmico, de polifonia e de intertextualidade, com o intuito de identificar e reconstituir o discurso de parto enunciado pelas mulheres gestantes que participaram de ação educativa desenvolvida.

\section{ETAPAS DO ESTUDO}

O presente estudo foi desenvolvido com a clientela de mulheres primigestas de um centro de saúde escola localizado em um município do interior do Estado de São Paulo.

A ação educativa desenvolveu-se por um periodo de sete meses, em treze encontros, contemplando uma entrevista individual no início e uma reunião de avaliação do trabalho educativo em um momento posterior ao parto. Todos os encontros foram registrados por aparelhagem de áudio-gravação com o devido consentimento das participantes.

Em relação às condições de produção, o discurso analisado foi aquele produzido durante a ação educativa proposta no estudo, que ocorreu em meio a um ambiente institucional, com a participação das interlocutoras $A, C, D, L, M$, gestantes primigestas e $P$, coordenadora da ação educativa e autora deste trabalho. $O$ conteúdo da ação educativa foi organizado a partir do interesse manifestado pelas gestantes.As 
caracteristicas do trabalho educativo proposto fizeram com que, durante todo o processo, o conteúdo de cada encontro mantivesse articulações com os demais.

Para efeito desta apresentação limitamos nossa análise no sentido de contemplar apenas os recortes, segundo a concepção desenvolvida por ORLANDI(1984), que permitiam a identificação do discurso de parto das gestantes e do processo de constituição desse discurso.

\section{ANÁLISE E DISCUSSÃo}

Partindo da consideração de que o parto foi expressado enquanto tema que mais despertava o interesse e preocupação do grupo, efetuamos um grande recorte do material obtido durante as reuniões, visando destacar as falas que a ele faziam referência. Na presente análise, o recorte é apresentado sob a forma de 8 seqüências discursivas, com o objetivo de identificar os sentidos do parto no discurso das gestantes. Os conceitos de processos polissêmico e parafrástico foram empregados com o intuito de verificar o(s) sentido(s) da palavra parto ou de sua representação no discurso das gestantes.

\section{O(s) Sentido(s) de Parto}

Recorte 1 - Seqüência discursiva produzida quando da devolução dos dados colhidos durante as entrevistas individuais:

P. ...é o parto mesmo que mais preocupa vocês?

L. A minha mesmo é a preocupação principal. Eu seique...Ave Maria!..Cruz!...Ave! É mesmo! Eu só me preocupo mesmo é com essa hora.

C. Eu também. 
D. Eu tenho medo de ficá lá no hospital, né, três dia, quatro dia...Ai, meu Deus! Eu quero ganhá no dia e i embora no mesmo dia.

P. Porque?

D. Ah! Eu tenho medo de injeção, essas coisa...

P. Não é bem do hospital que você tem medo, mas das coisas que são feitas no hospital,né?

D. Eu nunca entrei...nunca fui, né?

P. ...nem para visitar alguém?

D. Não. Eu fui...visitá um amigo meu... ah! Menina, é tão ruim...tinha uma menina soltando sangue pelo nariz. Eu não sei o que era mas,...Ah! Menina, a gente tá lá...sente até um calô...de vê aquele negócio soltando pelo nariz...

L. Deve só um absurdo o hospital...Eu também tenho medo do atendimento, sei lá como é que as enfermeira trata...

P. E as outras? É o parto mesmo?

A. Eu também acho.

M. Eu também.

No primeiro enunciado, embora $L$ não explicite a razão pela qual o parto se constituia como sua principal preocupação, ela expressa seu medo, seu distanciamento frente ao parto, indiretamente por meio das interjeições: Ave Maria! Cruz!.

Ao estudar processos enunciativos ligados às orações no contexto do discurso religioso católico cristão, GUIMARÃES(1987) observa que o sentido de interjeições do tipo credo!, etc., vem da relação com o Credo nome da oração, que em seu sentido original significaria creio, portanto o mal que se afaste!, com as mudanças nas condições 
de produção do discurso religioso, as mesmas deixaram de ser fundamentalmente religiosas para designarem o distanciamento, o espanto, o medo do locutor.

Tomando o conceito de dito em oposição ao não-dito, desenvolvido por ORLANDI(1989) consideramos que para não dizer o medo, ou seja, para não admitir o seu medo frente ao parto, $L$ o disse de outra forma, com o uso das interjeições.

No segundo enunciado $L$ revela um outro medo,... eu também tenho medo do atendimento, sei lá como é que as enfermeira trata..., que não o explicita enquanto motivo a do medo do parto e sim como o medo do atendimento que ela vai receber das enfermeiras por ocasião de sua internação para o parto.

$\mathrm{Na}$ fala de $\mathrm{D}$ surge o emprego de medo relacionado ao hospital. ...tenho medo de ficá no hospital...Ai meu Deus! Eu quero ganhá no dia e i embora no mesmo dia. Ao ser questionada sobre a causa de seu medo, D o atribui ao ...medo de injeção, essas coisa..., e medo pelo fato de nunca ter estado no hospital, ...eu nunca entrei...nunca fui, né? D emprega o sentido de medo do hospital de duas formas, expressando diretamente o seu medo de ficar no hospital e ainda reforçando-o por meio da interjeição Meu Deus!, com o mesmo sentido de afastamento empregado por $\mathrm{L}$, e o medo do hospital enquanto espaço de realização de procedimentos que a amedrontam. $D$ relata nunca ter ido ao hospital mas, ao mesmo tempo, ela afirma que já ter estado no hospital para visitar um amigo. $\mathrm{O}$ fato que ela omite, mas que está implícito, não-dito, em sua fala é o de que nunca esteve no hospital na condição de paciente, isto é, nunca esteve internada. Desta forma observamos a intertextualidade, ou seja, a relação de sentidos, do discurso de medo do hospital, emitido por $D$, com seu próprio discurso em relação ao hospital, construído a partir de uma experiência anterior negativa.

Recorte 2 - Seqüência discursiva produzida no momento em que solicitamos ao 
grupo que explicitasse os aspectos de interesse em relação ao parto:

P. O que vocês acham importante saber sobre o parto?

L. Tudo, desde a primeira dô até a última.

P. Só a dor?

A. Não, depois vem a alegria, né?

Nesta seqüência, o emprego da palavra parto se apresenta relacionado à dor na fala de L. O emprego da palavra alegria por $A$ não se contrapõe ao sentido de dor, mas surge em referência ao evento posterior ao parto, a alegria do nascimento. Assim, A não descarta o sentido de dor que $L$ correlaciona ao parto.

Recorte 3 - Seqüência discursiva produzida quando levantamos junto ao grupo as alterações emocionais percebidas em função da gravidez:

L. Eu mesma me sinto bem agora, mas no começo eu pensei: Meu Deus! Será que eu escapo dessa?

Mais uma vez $L$ expressa seu medo indiretamente por meio da interjeição: $M e u$ Deus!, porém além de não explicitar o sentido do seu medo ela tenta amenizá-lo por meio do emprego do verbo pensar na forma passada de conjugação. Afirmando que no início tinha esse pensamento mas que no momento se sente bem, deixa implícito que superou essa preocupação.

Por outro lado, em uma seqüência discursiva que se dá em um momento posterior, representado pelo Recorte $4, \mathrm{~L}$ retoma seu medo.

Recorte 4 - Seqüência discursiva produzida em um momento no qual nos ausentamos do grupo e as gestantes travaram diálogo livre: 
M. Vocês continuam com enjôo?

D. Não, o meu acabô.

L. O meu também. Por que? Você continua?

M. Não, eu só tive no começo.

L. O meu passô... Agora eu fico assim num nervosismo, não sabe? As vezes. eu penso que eu vô morrê, é verdade! Eu fico pensando que vô morrê.

Nesta seqüência, extraida de uma reunião que ocorreu posteriormente àquela da qual foi extraída a seqüência representada pelo Recorte $3, \mathrm{~L}$ retoma seu medo, colocando-o enquanto medo atual, utilizando para isto o verbo pensar na forma presente de conjugação e ainda o explicita enquanto medo de morrer:...eu penso que eu vô morrê. Em relação às condições de produção da seqüência retratada pelo Recorte $3 \mathrm{em}$ comparação ao Recorte 4, o dado que se altera decorre da ausência de P. Este fato nos leva acreditar que $L$ se sinta menos constrangida de revelar o seu medo à medida em que ocorre maior interação do grupo ou que somente na ausência de $P, L$ consiga expressar verdadeiramente o seu medo. Neste sentido talvez $o$ fato de $L$ identificar $P$ como profissional de saúde do serviço que se propõe a desenvolver uma atividade educativa com vistas a diminuir a ansiedade do grupo, conduza $L$ a emitir um enunciado que corresponda mais à expectativa de $\mathrm{P}$ do que à expressão verdadeira de seus sentimentos em relação ao parto.

Nesta mesma seqüência $L$ emprega a palavra nervosismo que, embora de maneira não explicitada, pode estar expressando seu medo em relação à morte.

Recorte 5 - Seqüência discursiva produzida durante a discussão a respeito da idade gestacional de cada participante:

L. Eita, mulhé, então eu vô passá pelas agonia primeiro do que vocês. 
Neste recorte L emprega a representação de parto enquanto agonia que se assemelha à representação já utilizada anteriormente na seqüência retratada pelo Recorte 2, parto como dor e, agora, agonia.

Recorte 6 - Seqüência discursiva produzida no momento em que o grupo tece comentários após a exibição de um vídeo-cassete sobre os tipos de parto:
A. A gente olhando parece fácil , mas na hora... eu fico morrendo de medo...
P. Por que?

A. Ah! Sei lá...eu não sô de acostumá com o parto normal, eu tô morrendo de medo...

P. Você tem mais medo de que?

C. Eu acho que é melhor.

L. Eu acho.
A. Ai! Dá um desespero.
C. Pelo jeito é melhor o normal...

L. Não, assim...olha, sei lá, parto normal, eu sei que a pessoa sofre porque está sentindo tudo, né, mas cesariana a gente vai sentí depois, e não é um dia só...dois como no parto normal, pode só no máximo dois dias, né P?

P. É...na verdade a mulher poderia sair andando da sala de parto, não se faz isto porque as pessoas entram e saem da sala, de maca, por causa da forma que o hospital está organizado e também por causa da anestesia que é feita no primeiro parto...senão, ela poderia até sair andando da sala de parto se quisesse. Agora, na cesariana recuperação é mais demorada porque é uma operação...

L. Eu não, eu só fazia cesariana se fosse o último jeito... 
C. Ai, Credo! (interjeição empregada em relação à cesariana)

P. A cesariana é uma operação e pode ter os riscos que qualquer operação tem, infecção... Agora, sentir dor... Do que você tem medo A?

A. Ah! Eu tenho medo do parto, né?...

P. Mas, medo do que?

A. Eu não sei...é uma cisma...sei lá...

L. É medo da dor, é?

A. Ai, dá um nervoso.

Nesta seqüência discursiva $A$ especifica seu medo em relação ao medo do parto normal, ...eu fico morrendo de medo...eu não sou de acostumá com o parto normal, eu tô morrendo de medo... que não é observado no Recorte 1. Contudo, ainda deixa não-dito a razão pela qual tem medo do parto normal, embora o represente pelo uso das palavras desespero e nervoso. Tomando em consideração as condições de produção dessa seqüência verbal, podemos observar que, à exceção de $A$, as demais interlocutoras emitem discursos em defesa do parto normal, em contraposição ao parto cesárea. $C$, inclusive, reforça o seu distanciamento do parto cesárea por meio do emprego da interjeição: Credo!, conforme o sentido já anteriormente discutido.

No discurso, o espaço no qual se dão as representações sociais das situações concretas no discurso é constituido de significações que, ORLANDI(1988) chama tecnicamente de relações de força do discurso, ao se remeter ao conceito de formações imaginárias. Segundo PÊCHEUX(1988) estas são as regras de projeção estabelecidas por qualquer formação social, que relacionam as situações concretas e as representações dessas situações no interior do discurso, a partir da consideração de que todo falante $e$ todo ouvinte ocupa um lugar na sociedade. As relações de força do discurso, na seqüência 
discursiva em questão, fazem prevalecer o discurso do parto normal, ao qual $\mathrm{A}$ não contra argumenta com o discurso do parto cesárea. Não se observa tensão entre o processo parafrástico e polissêmico, há o predomínio do processo parafrástico por meio do sentido dominante de parto normal em oposição ao parto cesárea. O controle da polissemia, ou seja, o controle da possibilidade de outro sentido de parto que não fosse o de parto normal é efetivado pelos discursos de C, L e P.

Recorte 7 - Seqüência discursiva produzida durante a discussão sobre a anestesia peridural no parto normal:

L. Por exemplo, aquela anestesia que dá assim de lado, mesmo que seja parto normal, eu não sabia que dava aquela anestesia nas costelas...

D. Mais dá.

P. Não é na costela, é na coluna.

L. É nas costas...eu não sabia.

D. Dá bem no meio.

P. É na coluna...

D. É, dá uma agonia de pensá...

Nesta seqüência, D retoma o medo, já expressado em relação aos procedimentos técnicos realizados no hospital, neste caso mais especificamente na assistência ao parto: agonia de pensá na anestesia.

Recorte 8 - Sequêencia discursiva produzida em um momento no qual se dava uma discussão sobre o parto normal e o parto cesárea:

L. ...Eu só penso nos ponto. Os ponto é que...eu tenho medo ...só pra mim, prá mim que o nenê nasçê não dói, só dói os ponto... Isso incasquetô na minha cabeça, os 
ponto e...não sai.

A referência que $L$ faz do medo a partir dos pontos também se assemelha ao emprego que D faz no Recorte 1 e no Recorte 7, medo de injeção, medo de anestesia, medo dos pontos.

Apesar das diferentes formas pelas quais o parto e sua referência se apresentam no processo discursivo, há por trás delas, a predominância de um sentido dominante de uma mesma formação discursiva. O sentido negativo de algo tido como sinônimo de dor, agonia, que vem associado à morte, cuja assistência envolve procedimentos técnicos desagradáveis e se dá um em espaço físico, o hospital, que por sua vez é estranho, etc.. Sob a falsa aparência de polissemia, enquanto possibilidade de sentidos diferentes, 0 processo predominante que se instala é o parafrástico, ou seja, é o mesmo sentido dito de outras formas. Mesmo quando A emprega a palavra alegria, ela não foge ao sentido dominante da formação discursiva, onde o parto é dor, mas o nascimento é alegria. Não se observa tensão entre sentidos diferentes, apenas a repetição das operações que sustentam o possivel de ser dito na formação discursiva a qual pertence.

Corroborando este achado, PAMPLONA(1990) faz referência a uma pesquisa que investigou imagens idealizadas de mãe junto a gestantes e profissionais que se preparavam para trabalhar com grupos de mulheres gestantes, cujos resultados apontam que as vivências de dor, de medo, de desconhecimento e subjugamento ao poder médico, inter-relacionadas e presentes no parto, podem ser entendidas dentro do processo de sujeição da mulher e mitificação da maternidade. Segundo a mesma autora, a dor no parto como valor ideológico do sofrimento inerente ao exercício da maternidade tem raízes, para a civilização ocidental judaico-cristã, na própria Biblia Sagrada. Esta ideologia dominante que vincula a dor como algo inerente ao parto está profundamente arraigada até os nossos tempos e é veiculada por toda a rede social. Assim, as próprias gestantes 
ao mesmo tempo que receiam a dor do parto também acreditam que somente através dela se expressarão verdadeiramente como mães amorosas. Neste sentido, as gestantes, principalmente aquelas pertencentes às classes populares que não contam com a anestesia peridural no parto normal, temem a dor e a sua própria morte ou a do feto. Embora desconheçam as estatísticas de mortalidade se reportam às histórias concretas de mortes de parentes, amigas ou vizinhas durante o parto. A autora ainda observou a vivência de outros temores presentes nas mulheres de classes sociais distintas, originadas pelo desconhecimento do processo de parto no contexto da repressão à sexualidade feminina.

O silêncio e o ocultamento do saber sobre a sexualidade não é vazio de significado, é um silêncio que significa a transmissão de um modelo de ser mulher, no qual o não saber, o desconhecimento é entendido como algo natural à expectativa de conduta adequada à condição feminina. Neste sentido os tabus, preconceitos e regras de conduta que envolvem a questão da sexualidade, constituem-se em estratégia do silêncio através da qual a sociedade exerce o controle sobre o corpo da mulher(PAMPLONA, 1990).

A mulher gestante, desapropriada do controle sobre seu próprio corpo, tanto pela negação do saber sobre sua sexualidade quanto pela assistência fragmentada que a transformou em mero objeto de cuidado, entrega-se submissa ao médico enquanto detentor do saber e deixa cada vez mais de viver criativamente a experiência do parto.

O deslocamento do lar enquanto cenário original onde acontecia o parto, observado com o progresso tecnológico da obstetrícia, introduziu a futura mãe em um ambiente totalmente estranho e impessoal, o hospital, no qual passa a receber os cuidados de pessoas desconhecidas, os profissionais de saúde, que não fazem parte da comunidade na qual vive a mulher. 
KITZINGER(1987) observou que a internação hospitalar por si só provocava a elevação dos niveis de pressão sanguinea arterial em gestantes que estavam sendo preparadas para o parto.

Entendemos os vários medos manifestados pelas gestantes neste estudo (medo de injeção; medo da anestesia; medo de ficar no hospital; medo do atendimento prestado no hospital) no contexto do desconhecimento da rotina de atendimento médico e hospitalar relacionada à assistência ao parto. O desconhecimento da fisiologia do processo de parto pode também estar relacionado à expressão do medo de morrer manifestada por uma das gestantes.

A partir dos recortes efetuados não foram encontradas pistas explicitas de intertextualidade, ou seja, pistas de relação de sentidos do discurso de parto enunciado pelas gestantes com outro discurso. Apenas o enunciado de $D$ contemplado no Recorte 1, estabelece uma relação de sentidos do discurso de medo do hospital com o seu próprio discurso que teve origem em uma experiência anterior. Deste modo, efetuamos um novo recorte no material com o objetivo de identificar o(s) discurso(s) que serviram de matéria-prima na constituição do discurso de parto das mulheres gestantes envolvidas.

\section{O Processo de Constituição do Discurso de Parto}

Com a finalidade de revelar a relação de sentidos do discurso do parto, apresentamos 3 seqüências discursivas, nas quais as pistas da intertextualidade eram recuperáveis no próprio texto. Para esta análise utilizamos como instrumento central a concepção de polifonia.

Recorte 9 - Seqüência discursiva produzida a partir do nosso questionamento junto ao grupo, a respeito do conhecimento que tinham sobre o parto: 
L. O pessoal fala e conta, põe medo só na hora...

Nesse enunciado, através da noção de polifonia, concepção especifica da heterogeneidade, que concebe a existência de dois tipos de personagem em uma enunciação, os enunciadores e os locutores, é possivel recuperar a intertextualidade do discurso de parto. O locutor é aquele que se apresenta como o eu do discurso, o seu responsável, e o enunciador é o ser cuja voz está presente na enunciação, sem que the possa atribuir palavras precisas. $O$ enunciador não fala, mas a enunciação permite expressar seu ponto de vista(MAINGUENEAU, 1989).

No enunciado acima, L põe em cena, em seu próprio enunciado, a posição de um enunciador genérico: $O$ pessoal. L não se expressa como o eu do enunciado, ou seja, como locutora do enunciado, porque o mesmo não é dela, é de outro. Dessa forma, L não se responsabiliza pelo enunciado.

Recorte 10 - Seqüência discursiva que se instala a partir da discussão sobre a percepção individual frente ao parto, após a projeção do video-cassete sobre os tipos de partos:

L. Eu nem penso, se a gente pensá, a gente só pensa besteira, né. Os outro falam assim das coisa, eu digo: É ? Eu fico tranquila, porque tantas passam, será que só vai aconteçê o pior comigo? Eu não...

D. Isso é né,.... tantas já passô...

L. Não é tão difícil porque uma fala que tem medo de engravidá: "Eu não quero não"... depois diz: "Eu ainda vô tê outro". E já sabia, então não é esse bicho de sete cabeça .....

D. É, deve sê não, porque já sabia como era né, e ainda foi arrumá otro. Se sentia dô, se era ruim elas não arrumava otro, ficava só com um. Qué tê quatro, cinco... 
C. Minha mãe teve doze, trés aborto...

D. Minha mãe teve oito...

P. Então quer dizer que por mais que as mulheres falem que dói e é ruim, vocês acham que não é bem assim...

D. Se fosse ruim desse jeito...

L. Não, olhe se fosse desse jeito, mulé nunca mais queria sabê de hôme na vida dela...todas se separava.

Na primeira seqüência verbal produzida, $L$ já se coloca no enunciado, como locutora: Eu nem penso, ao mesmo tempo se inclui em outra instância do enunciado: a gente, se referindo a um enunciador enquanto pessoa genérica. Em seguida, $L$ se distancia da opinião do enunciador: os outro, quando deixa implícito que não se importa com o que os outros dizem. Assim, L não se inclui entre o enunciador genérico os outros.

Na seqüência, L questiona o discurso da mulher, enquanto enunciador genérico, responsável pelo enunciado, colocando como falsa essa opinião a partir da própria contradição do enunciador, que L mostra ao fazer duas citações que em sua opinião se contradizem. Desta forma L, nega o pressuposto do enunciador, entendido como a verdade na qual se baseia o enunciador. A negação realizada, segundo o conceito de MAINGUENEAU(1989) é do tipo polêmica, uma vez que L, enquanto locutora contesta explicitamente a asserção do enunciador presente em sua fala.

D também compartilha da opinião de $L$, ao se colocar, em seu enunciado, como locutor que não compartilha da opinião do enunciador genérico, ela, elas, negando o pressuposto no qual se baseia o enunciador.

Para reforçar o posto no qual se baseiam, L e D tomam como exemplo a própria 
mãe e, assim, remetem o discurso genérico de parto aos seus próprios discursos referindose a uma figura feminina que faz parte de suas história. Elas não falam mais de mulher, enquanto sujeito do mundo, mas de suas mães, sujeitos concretos, estabelecendo ai a relação de sentidos, a intertextualidade. Dessa forma, mais uma vez derrubam o pressuposto do enunciador genérico.

Por meio da polifonia, o locutor pode introduzir em seu enunciado, posições divergentes ou que respaldem a sua opinião. Para MAINGUENEAU((1989) a concepção de polifonia empresta toda a sua força à metáfora teatral, por meio da inserção de diversos personagens na enunciação, o locutor não falaria diretamente, mas o faria por meio de sua adesão as enunciações tidas por ele como sérias.

Recorte 11 - Seqüência discursiva produzida em um momento posterior ao parto das interlocutoras $\mathrm{C}$ e $\mathrm{L}$.

L. O, minha irmã, minha irmã, ela teve uma menina...Eu tinha medo dos pontos, porque ela dizia que sofreu tanto, era um inferno... Eu sofri, porque a gente tá costurado, né?

C. $E$.

L. Mas ela, com sete dia tava em cima duma cama chorando...Eu, com quatro dias, caiu dois ... só tem uma presinha fininha prá caí agora. E eu fiz tudo, tudo, tudo ... só não fiz lavá roupa, roupa grossa assim, mas o resto eu que faço tudo, na minha casa eu que faço tudo, não sinto nada...

A partir do enunciado de $L$, detectamos pistas da intertextualidade que é constitutiva do discurso. Ao citar a experiência da irmã, o discurso do medo dos pontos presente no Recorte 8, que se apresentava como uma voz anônima que falava nela, explicita-se neste recorte, quando $L$ revela a voz anônima, sua irmã. $A$ contradição se revela a partir da 
consideração de que o discurso de medo dos pontos de $L$, era em realidade, o discurso de medo dos pontos da irmã, que falava em $L$.

Neste sentido, enquanto técnica de Análise de Discurso, a intertextualidade evidencia a ilusão discursiva do sujeito, efeito da ideologia. A ideologia faz com que o sujeito acredite ser a fonte exclusiva de seu discurso, quando na realidade ele retoma os sentidos pré-existentes.

A análise de todos os recortes evidenciam a contradição que permeia o discurso das gestantes. Ao negarem o discurso de medo do parto emitido por outras pessoas, elas negam o discurso de medo do próprio parto, pois a relação de sentidos do seu discurso com outros discursos construiu-se em algum momento, em algum lugar. Caso contrário elas não teriam esse discurso, uma vez que por serem gestantes primigestas não contam com a experiência do parto enquanto fato gerador de conhecimento e opinião. Embora não expressado o discurso do profissional de saúde, enquanto matéria-prima de estabelecimento de relação de sentidos ao nivel do texto analisado, cabe a indagação sobre o função do profissional de saúde enquando veículo de divulgação da ideologia dominante de atrelamento do sofrimento e da dor como componentes inerentes ao processo do parto. Não se trata de negar a dor do parto, nem de afirmá-la como resultante exclusiva do condicionante cultural, entretanto verificamos através da vivência de muitas mulheres e da nossa própria experiência, que a dor não necessariamente se apresenta como inerente ao parto.

No próprio processo de análise, a propósito de evidenciarmos os vários empregos da palavra parto e sua representação nos discursos das gestantes, a questão do autoritarismo se revelou enquanto elemento constitutivo da história do processo discursivo estabelecido a partir da ação educativa desenvolvida. 
As condições de produção caracterizam e constituem o discurso e como tal devem também ser entendidos enquanto objeto de análise(ORLANDI,1987). O espaço de interlocução estabelecido deu-se em meio a uma relação pedagógica na qual o autoritarismo se fez presente de alguma forma. Essa consideração poderia explicar tanto a não expressão do temor de A em relação ao parto normal, dada as relações de força no discurso observável no Recorte 6, quanto à explicitação do medo de morrer que L omite no Recorte 3 mas o expressa no Recorte 4. Neste caso específico a identificação de $P$ enquanto profissional de saúde investido da autoridade que o domínio do discurso cientifico lhe confere pode ter interferido no processo discursivo estabelecido.

Ainda, a propósito dessa discussão efetuamos o recorte de um enunciado de $L$ sobre o medo dos pontos:

L. ...Eu sofri porque a gente tá costurado, né...

Embora o termos "costura" e "rafia" possam ser muito próximos, a natureza, a finalidade, os procedimentos e instrumentos são bastante distintos. Assim, provavelmente o sentido de costurado para $L$ é diferente do sentido que o termo episiorrafia* tem para o profissional de saúde, mas a relação de sentidos entre a palavra costurado e a episiorrafia se construiu em algum momento. É com relativa frequência que os profissionais de saúde, enquanto educadores, sob a justificativa da democratização do saber científico, utilizam palavras, expressões de domínio comum com o intuito de simplificar ou exemplificar um termo técnico. Ou seja, realizam concessões lingüisticas sem, contudo, levar em consideração as formações discursivas nas quais o(s) sentido(s) das palavras ou expressões se constituem, isto é, que o(s) sentido(s) são determinados pelas posições ideológicas em jogo no processo sócio-histórico no qual são reproduzidos(PÊCHEUX,1988). Na tentativa de sobrepujar as barreiras lingüisticas dissimulam as diferenças de classe social. Desta forma, o exagero na busca de uma relação pedagógica democrática, pode transformá-los inconscientemente, em meros 
reprodutores da relação de dominação, a partir de um discurso subliminarmente autoritário, no qual o objeto está encoberto pelo dizer e, permanece assim, na esfera do seu domínio exclusivo.

Um outro ponto que se mostrou relevante na análise das seqüências representadas neste tópico, é o de que as gestantes já apresentavam em seu discurso o sentido dominante do parto, como parto normal, que foi reforçado durante o processo discursivo, por meio das relações de força que se estabeleceram. Contudo, a relação de sentidos estabeleceuse em outros momentos, em momentos anteriores à ação educativa.

Cabe, ainda relatar que, todas as gestantes, com exceção de $A$, além de vivenciarem o trabalho de parto de maneira bastante tranqüila também o finalizaram com o parto normal. Quanto a gestante A, que relutou em explicitar a razão de seu temor de medo de parto normal, apresentava uma história bastante particular de um vinculo familiar bastante complicado. Seu pai, muito autoritário, era também bastante rigido e discriminatório em relação aos papéis sexuais. A tentativa de libertar-se do domínio do pai encaminhou-a precocemente à gravidez $\mathrm{e}$, por conseqüência ao casamento, sem que tivesse tido qualquer possibilidade de estruturar-se emocionalmente para enfrentar o processo da gravidez e do parto de modo mais satisfatório. Essa gestante apresentou um trabalho de parto prolongado, que necessitou de indução medicamentosa e finalizouse com um parto cirúrgico. Este dado nos faz refletir sobre a necessidade de repensar a prática dos serviços de saúde no sentido de buscar a integração de uma assistência já fragmentada.

\section{REPENSANDO A PRÁTICA}

A realização deste estudo representou, enquanto pesquisadora, a possibilidade de concretizar algumas crenças pessoais em relação ao desenvolvimento de ações 
educativas a partir do universo de experiências dos sujeitos envolvidos no processo.

Embora não contasse com experiências prévias na utilização da metodologia de pesquisa participante e da análise de discurso, enquanto instrumento de avaliação de práticas educativas, acreditamos que o emprego destas abordagens em nossa prática educativa e assistencial contribuiu significativamente tanto no aprimoramento de nossa formação como pesquisadora, quanto de nossa prática como enfermeira e docente. $\mathrm{Na}$ medida em que proporcionou um maior conhecimento e uma maior aproximação da realidade vivida pelos sujeitos das práticas de saúde, a utilização destas metodologias permite aprimorar as possibilidades de intervenção mais efetiva dos profissionais de saúde junto às gestantes, apontando para a melhoria das condições de realização de um trabalho transformador.

Consideramos que a adoção da perspectiva de educação empregada neste estudo pelos serviços de saúde passa pela necessária instrumentalização dos profissionais, a fim de que seja possivel a crítica e a ruptura do entendimento e, conseqüentemente, da reprodução da ação educativa em saúde como instrumento regulador e disciplinador de normas e condutas.

Acreditamos que os resultados deste estudo possam trazer contribuições no sentido de enriquecer a reflexão sobre a avaliação qualitativa de serviços. A partir da consideração do usuário como sujeito e não objeto das ações de saúde, a avaliação deveria ser entendida muito mais como busca da adequação dessas ações às necessidades da clientela do que ao cumprimento dos programas institucionais.

\section{CONCLUSÕES}

Em nivel especifico, os resultados deste estudo permitem concluir que: 
A identificação do discurso dominante relativo aos temores do parto enunciado pelas gestantes possibilitou o direcionamento da ação educativa com vistas a atender mais adequadamente às expectativas das mesmas.

O sentido dominante do discurso de parto emitido pelas gestantes correspondeu ao sentido de parto aceito e legitimado pelos serviços de saúde.

O emprego da Análise de Discurso possibilitando a apreensão do processo de constituição do discurso de parto, permitiu por meio da identificação da contradição no discurso genérico de parto a construção de um discurso criador por parte das gestantes.

Acreditamos que uma outra forma de favorecer a construção de um discurso criador é dado pelo emprego de recursos que favoreçam a aproximação concreta das gestantes à realidade da assistência obstétrica e do processo de parto. Nesta pesquisa, as gestantes tiveram a oportunidade de visitar o setor obstétrico do hospital municipal e de contar com recursos audio-visuais (vídeo-cassete e projeção de slides) sobre o processo e tipos de parto.

A despeito da metodologia adotada neste estudo, as relações de poder decorrentes dos diferentes modos de inserção social das gestantes em relação ao pesquisador, interferiram no modo de apropriação da fala.

Em nivel global, entendemos que o estado de subdesenvolvimento econômicosocial e cultural do pais constituem obstáculos à vivência tranquila da gravidez, parto e puerpério. Apesar de este estudo não ter se proposto à superação de tal condição, a vivência da maternidade representa um canal aberto às possibilidades de ação institucional dos profissionais de saúde na promoção de práticas educativas dirigidas às mulheres. 
As práticas educativas que se desenvolvam a partir da perspectiva que busque integrar aspectos biológicos, emocionais e sócio-econômico-culturais no entendimento dos processos da gravidez, parto e puerpério, podem trazer contribuições no sentido de preencher a lacuna decorrente da fragmentação da assistência prestada à gestante.

Conhecimentos que favoreçam a compreensão do modo pelo qual os discursos se constituem representam um instrumental de grande relevância na reflexão e reorientação da prática educativa desenvolvida pelos profissionais de saúde.

\section{REFERÊNCIAS BIBLIOGRÁFICAS}

BRANDÃO, H. N. Introdução à análise de discurso. Campinas, SP, Pontes, 1990.

GUIMARÃES, E. Credo ou creio. In: Orlandi, E. L. P. Palavra, fé, poder. Campinas, Ed. Pontes, 1987. p.81-9.

KITZINGER, S. Mães: um estudo antropológico da maternidade. Lisboa, Ed. Presença, 1987.

LAGAZZI, S. M. O juridismo marcando as palavras: uma análise do discurso cotidiano. Campinas, 1987. [Dissertação de Mestrado - Instituto de Estudos da Linguagem da UNICAMP].

MAINGUENEAU, D. Novas tendências em análise de discurso. Campinas, Ed. Pontes/ UNICAMP, 1989.

MALDONADO, M. T. Psicologia da gravidez. 4ª ed. Petrópolis, Ed. Vozes, 1976.

NOZAWA, M. R. Ação educativa participante com gestantes: a análise de discurso como instrumento de avaliação. São Paulo, 1991. [Dissertação de Mestrado - Faculdade de Saúde Pública da USP].

ORLANDI, E. L. P. Discurso e leitura. Campinas, Ed. Cortez/UNICAMP, 1988.

ORLANDI, E. L. P. Linguagem e seu funcionamento: as formas do discurso. $2^{\mathrm{a}}$ ed. Campinas, Ed. Pontes, 1987. 
ORLANDI, E. L. P. Segmentar ou recortar.In: Lingüística: questões e controvérsias. Uberaba, 1984. p.9-26. (Série Estudos, 10)

ORLANDI, E. L. P. Silêncio e implicito - produzindo a monofonia. In: Guimarães, E. História e sentido na linguagem. Campinas, Ed. Pontes, 1989. p.39-46.

PAMPLONA, V. Mulher, parto e psicodrama. São Paulo, Ed. Àgora, 1990.

PÊCHEUX, M. Semântica e discurso: uma critica à afirmação do óbvio. Campinas, Ed. UNICAMP, 1988.

XAVIER, D. et alii. Questões femininas para a ordem médica: o feminismo e o conceito de saúde. In: Labra, M. E. Mulher, saúde e sociedade. Petrópolis, Vozes, 1987. p.203-22.

Summary: This paper is part of a study carried out with a group of women, at a school health centre, experiencing their first gestation. The study aims at developing and evaluating a participative educative action. Such action has been developed from a pedagogic relation perspective based on dialogue and active participation of the women in in the educative process. Thus the methodological framework derived from the concept of freeing education and participation research methodology. Both the data used and analysis perfomed refer to the discussion on delivery - the central issue of the whole educative process. The use of Discourse Analysis as an evaluative tool of the action allowed the identification of the predominantly negative meaning of delivery in the pregnant women's discourse as well as the discussion of the production process of the discourse. Such discussion indicates strategies that promote the overcoming of the negative load that will subsidise the educative practice of health professionals towards this specific clientele group.

Key words: first gestation; education action; discourse analysis; freaing education; participatory research methodology. 